King on the thermal etching of silver shows that the etch patterns differ widely, depending on the crystallographic orientation of the material. Recent developments in France of scanning and emission microscopes were briefly described by Prof. Grivet. In the scanning microscope, which he is developing in collaboration with Prof. Guinier, a fine electron beam falls on the specimen, and the $\mathrm{X}$-rays generated are detected in a Geiger-Müller counter. Dr. P. Coheur, of C.N.R.S., Liège, in referring to the paper by Trotter, McLean and Clews, mentioned some of his own investigations on steel specimens. He has extracted the carbides from the steels by the alcoholic iodine method, for X-ray examination. Following on this topic, Dr. Clews gave a brief account of some recent work on the tempering of martensite, comprising an electron microseope study, the examination of the etched metal surface by electron diffraction reflexion patterns, and subsequent $\mathrm{X}$-ray examination of alcoholic iodine residues. The results are in excellent agreement among themselves and with some unpublished work by Jack.

Since its inception in 1932 a very great amount of development, both of the instrument and its associated techniques, has been necessary; but from the papers presented and the discussion which followed, there is no doubt that the electron microscope has now become an important tool for the study of metal surfaces. An interesting exhibition of electron micrographs was arranged in the ante-room to the lecture theatre, and methods of replica preparation were demonstrated at the end of the meeting.

C. J. B. Clews

\section{BRITISH NON-FERROUS METALS RESEARCH ASSOCIATION NEW LABORATORIES}

CIR BEN LOCKSPEISER, secretary of the De$D$ partment of Scientific and Industrial Research, opened extensions to the laboratories of the British Non-Ferrous Metals Research Association on February 13. This was made the occasion of a Press conference at which some fifty representatives of the daily and technical Press were present. After an introductory talk by Sir Ben, the visitors toured the laboratories and saw work in progress. On the next three days the laboratories were open to some seven hundred guests, mostly from the technical staffs of member companies, but with many from Government departments, universities and research associations.

The new extensions were provided by reconstruction of a building destroyed during the War ; they represent for the present the concluding stage of a programme of enlargement which has been in pro. gress for some years. The Association now has well-balanced facilities to undertake the work which the non-ferrous industry requires.

The basement of the new building contains the new metal-working laboratory, with equipment intended for the production of any special wrought metals required for use in the Association's experimental work. Such specimens have hitherto been provided by the willing and generous assistance of member companies at some inconvenience to themselves. The equipment of the metal-working laboratory includes a 500-ton down-stroke hydraulic press which can be used for extrusion or press forging; a 12 in. $\times 12$ in. rolling mill equipped with plain rolls for sheөt and strip production, and grooved rolls for the production of bar material ; two smaller presses (one for powder metallurgy), a drawbench, machine tools and other ancillary plant.

The first floor is devoted to the general metallurgy section, for which laboratory facilities have hitherto been inadequate. Equipment is available for the study of slag/metal and gas/metal reactions, and includes sensitive apparatus for the extraction of gases from metals and their subsequent analysis. A $7-\mathrm{kW}$. output high-frequency induction furnace is available for gas-extraction work where resistance heating is inconvenient, for oxygen determinations by vacuum fusion of metals in carbon and as a general tool in the study of equilibria at high temperatures. Studies are in progress of the copper/phosphorus/oxygen equilibrium and of properties of copper-smelting slags affecting smelting losses, a subject of interest to Commonwealth copper producers. These laboratories also contain various heat-treatment furnaces and a $20-\mathrm{kW}$. carbon resistor vacuum-furnace of the Kroll type, used, for example, in the melting of titanium : the Association is taking a very active part in research sponsored by the Ministry of Supply into the possibilities of titanium and its alloys. The general metallurgy section also includes the equipment for routine metallographic examination used in all the Association's researches. Special metallographic work has included the development of the use of diamond dust for metallographic polishing, for example, for thin coatings on hard-basis metals, and the design and construction of equipment for micro-hardness testing.

It should, however, be emphasized that these new extensions of the British Non-Ferrous Metals Research Association laboratories, important though they are, form only a part of the total space, apparatus and plant available, all of which were inspected by the visitors on the open days. In the present brief notes it is impossible to describe the entire establishment and the researches in progress : attention will therefore be limited to some facilities available for the application of physical and physico-chemical techniques and apparatus to the study of fundamental metallurgical problems.

In corrosion research, application is made of measurements of corrosion currents and electrode potentials, if necessary with continuous recording. Electrode potentials must be measured with instruments which take a negligible current, otherwise the electrode under observation might be polarized, yielding an untrue result. Measurements are therefore usually made with valve voltmeters or other instruments incorporating some degree of D.C. amplification. A number of instruments are in use (some adapted for continuous and multiple recording) which take maximum currents from $10^{-8}$ to $10^{-14} \mathrm{amp}$. In respect of the study of corrosion, mention may also be made of the polarograph; primarily an instrument for analytical purposes, this has been used for demonstrating differences in the character of supply waters which are not apparent from other methods of investigation. The various electro. chemical methods mentioned have been applied, for example, in the course of investigations on the corrosion of galvanized steel and of copper. Another electrochemical technique, the measurement of voltage-current curves over very short time-intervals, is being applied to the study of the anodic film which is believed to be of importance in the mechanism of electropolishing. 
The Association's physics laboratories are equipped with an electron microscope, an electron-diffraction apparatus and an $\mathrm{X}$-ray generator, with a wide range of cameras. The techniques thus available are applied as required throughout the Association's work both in its internal research programme and as ad hoc service to assist member firms in dealing with current technical problems. The electron microscope is proving of special value in the study of grainboundary structures, which have been found to be of great importance in the technical properties of alloys. Electron-diffraction has been applied usefully to the study of the adhesion of electrodeposits on aluminium alloys and to the examination of the oxide films formed on liquid and solid metals, while the X-ray equipment is in constant use for the identification of chemical compounds and for studies of the constitution and texture of materials. In the physics section also, measurements of surface energy and surface tension are throwing light on soldering, brazing and hot-dip metal coatings ; while multiplier photocells are being applied to the direct measurement of the intensities of spectral lines, in further development of the Association's well-known investi. gations on the spectrographic analysis of metals.

\section{CHEMICAL ATTRACTANTS FOR INSECTS : SEX- AND FOOD- ODOURS OF THE COTTON LEAF WORM AND THE CUT WORM}

\author{
By Prof. B. FLASCHENTRÄGER \\ AND \\ EL SAYED AMIN
}

Faculty of Science, Farouk I University, Alexandria

W

$\mathrm{E}$ have been investigating the cotton leaf worm (Prodenia litura, Fab.) and the cut worm (Agrotis ypsilon, Rott.), the most harmful pests of cotton in Egypt ${ }^{1-3}$. Female moths are found to attract the male moth and not vice versa, as with the gypsy moths ${ }^{4}$. If the females are separated in a glass chamber from the males, no attraction occurs. The odour of the female appears an hour after hatching and is restricted to the last two abdominal segments. The sex-odour disappears from the cut abdominal segments in a vacuum, but reappears again after $15 \mathrm{~min}$. under normal pressure. It disappears totally after one and a half hours. It can be extracted from the abdominal segments with purified ether, and the ethereal residue shows the same power of attraction as the living moth. This proves that the female attracts the male by one or more chemical substances and not by sound or radiation.

We have developed an apparatus (an odour. analyser) which enables us to study sex- and foododours chemically and biologically simultaneously. It consists of three parts : an odour-developer containing the females or the food, the odour-receiver with which we investigate the physical and chemical properties of the odours, and the odour-tester in which the males are able to migrate against the odour-stream and not the reverse. With this apparatus the sex-odour of the cotton leaf worm was found to be a volatile, neutral substance or mixture; it could be frozen out at $-20^{\circ}$ C. It was stable against dilute sulphuric acid and dilute sodium hydroxide. With concentrated sodium hydrogen sulphite we were able to extract the sex-odour from the air-stream. This suggested the presence of an oxo-group in the molecule.

We found that fermenting 'bouza', the Egyptian wheat-beer ${ }^{5}$ which is used in the Andree-Maire trap to attract the moths of cotton pests ${ }^{1,2}$, contains $\mathrm{a}$ volatile mixture, consisting mainly of ethanol and acetic acid. However, pure ethanol attracts very few moths, and acetic acid does not attract any moth; but a mixture of the two attracts many more. The bouza odour is volatile with steam and can be frozen out. It is stable with dilute sulphuric acid and 1 per cent formalin, but is partially destroyed by dilute sodium hydroxide. Concentrated sodium hydrogen sulphite had no effect on bouza-odour, in contrast to its effect on the female sex-odour.

The extraordinary sensitivity of the sense organs of insects enables us to investigate with our apparatus some of the chemical properties of sex- and foododours, in order to find the best way of enriching them and also to test the fractions of extracts.

Reports on this work were given on September 29, 1948, at Frankfurt before the Deutsche Physiologische-Chemische Gesellschaft (Angew. Chem., 61, $252 ; 1949$ ), and on November 30, 1948, at the Faculty of Science, Farouk I University, Alexandria.

1 Bishara, I., Bull. Soc. Roy. Entomol., 18, 288 (1943); Tech. and Sci. Service Bull., 114, 1 (1932) (Ministry of Agriculture, Cairo: Government Press).

'Willcocks, F., "The Insects and Related Pests in Egypt", 1, Pt. 2 (Cairo, 1937).

${ }^{3}$ Kamal, M., Proc. VI. Internat. Congress Entomol., Madrid, 1935, 2 , $567(1940)$.

${ }^{4}$ Haller, H. L., Potts, S. F., and Acree, F., J. Amer. Chem. Soc., 66, 1659 (1944).

"Monib, M., Fac. of Agriculture (Cairo, 1948).

"See also Dithier, A. M., "Chemical Attractants and Repellents" (London, 1947). Wigglesworth, V. B., "The Principles of Insect Physiology" (3rd, edit., London, 1947). Moncrieff, R. M., "Chemen im Dienste der Landwirtschaft und Imkerei"' (Wien, 1947).

\section{PERCEPTION AND MEASUREMENT OF ODOUR}

A LECTURE in Esperanto on "The Perception A and Measurement of Odour" was given by Dr. D. R. Duncan on January 17 at University College, London, at the conclusion of the annual general meeting of the British Esperanto Scientific Association. Dr. Duncan first reviewed the attempts which have been made by Linnæus ${ }^{1}$, Zwaardemaker ${ }^{2}$, Henning ${ }^{3}$, Crocker ${ }^{4}$ and others to evolve systematic classifications of the known types of odour, mainly on the basis of subjective judgments of similarity and dissimilarity. He felt that Zwaardemaker's was by far the best attempt; but that the real solution of the problem demands attack by other methods, including a quantitative approach. Dr. Duncan described the $p \mathrm{O}$ scale of odour intensity and various instruments which have been used for estimating odour intensities, including the Fair-Wells osmoscope ${ }^{5}$ (which is now an article of commerce) and an improved apparatus designed by Dr. G. H. Cheesman and himself. He gave reasons for assuming that there is a limited, though large, number of primary odours, other odours being produced by simultaneous stimulation of more than one type of receptor.

He then described unpublished work carried out by himself in a preliminary attempt to analyse 